\title{
El aborto en el derecho transnacional. Casos y controversias
}

Rebecca J. Cook, Joanna N. Erdman y Bernard M. Dickens (eds.) (2016)

México: FCE, CIDE

\section{Celeste Leonardi UNLP}

Esta colección de escritos analiza los desarrollos jurídicos sobre el aborto, desde una perspectiva del derecho transnacional durante los siglos XX y XXI. Desde una amplitud temática, la obra muestra la evolución del derecho que regula el aborto, partiendo del abordaje tradicional del derecho penal hasta arribar a la perspectiva de los derechos humanos de las mujeres.

Las/os autoras/es provienen de diferentes países y se dedican a la temática del aborto desde distintos ámbitos. En ese sentido, el libro aborda varias regiones geográficas y explora formas alternativas de tratar el aborto en el ámbito transnacional.

Esta obra resulta indispensable para visibilizar y comprender las ideas que influyen en la regulación y la jurisprudencia sobre el aborto y, por ello, es de especial interés para expertas/os que buscan teorías y experiencias innovadoras sobre el tema. Pero también es de interés para quienes se inician en la temática del aborto, en tanto recorre sus primeros debates jurídicos y judiciales.

El libro fue organizado en torno a cuatro temas principales: valores constitucionales y regímenes normativos; justicia procesal y acceso liberalizado; interpretación y reivindicación de los derechos individuales; y narrativas y significado social.

La primera parte, compuesta por cinco capítulos, se enfoca en la evolución de los valores constitucionales sobre el aborto y la protección de estos en los diversos regímenes jurídicos entendidos como instrumentos legislativos y de políticas públicas que las legislaturas utilizan y los tribunales revisan en la regulación del aborto.
En el capítulo "La constitucionalización del aborto", Reva B. Siegel analiza el origen de la normativa constitucional del aborto, su evolución en el tiempo y la influencia de los movimientos sociales en las sentencias de los tribunales. En esa línea, explora los principales fallos en Alemania y Estados Unidos, los cuales parten de dos valores diferentes: proteger la vida del feto y proteger los derechos de las mujeres, respectivamente. La autora describe los marcos normativos constitucionales contemporáneos que reivindican estos valores constitucionales en pugna, tomando la labor de solucionar el conflicto entre ellos.

Los capítulos siguientes de la primera parte abordan los marcos normativos en Portugal y Eslovaquia que validan los regímenes de consejerías, los cuales apuntan a proteger la vida del feto $y$, a su vez, respetan la dignidad y autodeterminación de la mujer.

En el tercer capítulo, Verónica Undurraga describe el principio de proporcionalidad como marco analítico para el control judicial de las normas y analiza la manera en que los tribunales han armonizado la obligación positiva de proteger la vida del feto con su obligación negativa de abstenerse de interferir en los derechos de las mujeres.

Seguidamente, en "Un enfoque funcionalista al derecho comparado del aborto", Rachel Rebouché cuestiona la metodología que se utiliza en los estudios comparados sobre las normas que regulan el aborto y examina un nuevo enfoque comparativo. Así, el método funcionalista estudia cómo las normas legales influyen en la práctica del aborto. La autora señala: "lo que puede ser relevante en el estudio de las normas sobre el aborto es cómo funciona de 
manera imprevista el derecho formal y cómo es a menudo frustrado por reglas informales".

La segunda parte profundiza la temática analizada por Rebouché sobre el vínculo entre el derecho y la práctica del aborto. Se organiza en tres capítulos desde perspectivas geográficas distintas. El primero analiza el giro procesal del Tribunal Europeo de Derechos Humanos, cuestionando la posibilidad y la forma en que los derechos del aborto de carácter procedimental pueden servir al fin sustantivo: el acceso a los servicios. La autora destaca una serie de arbitrariedades: "a una mujer se le pueden negar servicios a los que tiene derecho o se le pueden otorgar servicios a los que no tiene derechos".

En el segundo capítulo, Paola Bergallo estudia el giro procesal en el contexto argentino a partir de la confrontación entre la norma formal, que regula los permisos para abortar previstos en el artículo 86 del Código Penal, y las normas informales que consolidaron la prohibición total del aborto. Asimismo, Bergallo analiza el impacto del giro procedimental a partir de la sentencia de la Corte Suprema de Justicia de la Nación donde se pronunció específicamente sobre el artículo 86 del Código Penal.

En el tercer capítulo, Charles Ngwena destaca la importancia de la transparencia en las leyes sobre el aborto como una herramienta jurídica y como un complemento estratégico para reformar leyes y prácticas africanas sobre el tema a fin de promover el acceso al aborto seguro.

Los capítulos que componen la tercera parte analizan los marcos argumentativos de la reivindicación de los derechos individuales. Sally Sheldon examina el marco de referencia médico en relación con el aborto medicamentoso temprano. Señala que en Gran Bretaña la provisión de servicios de aborto permanece restringida por requisitos clínicamente innecesarios sobre dónde se pueden efectuar interrupciones y quién las puede autorizar y realizar.

En "El derecho a la conciencia", Bernard Dickens sostiene que el derecho humano de actuar legalmente y de acuerdo con su conciencia no es monopolio de quienes se oponen al aborto. En efecto, señala que los/as proveedores de servicios de aborto tienen derecho a ejercer esta práctica legal, a informar acerca de esta posibilidad y a remitir o derivar a las pacientes donde existan servicios adecuados y disponibles, de acuerdo con los principios que rigen su propia conciencia.
Julieta Lemaitre analiza los principales argumentos del constitucionalismo católico contra la regulación legal del aborto, propone a las/os defensoras/es de la despenalización formas productivas de abordar seriamente estos argumentos y estudia las posibilidades de resolución del conflicto entre los movimientos de defensa y los de resistencia a los derechos sexuales y reproductivos.

En "El aborto en el debate público brasileño", su autor presenta las estrategias jurídicas que se utilizaron en el Supremo Tribunal Federal de Brasil para hacer valer el derecho de las mujeres a interrumpir el embarazo de fetos anencefálicos y, de este modo, avanzar hacia el debate sobre la despenalización del aborto.

El quinto capítulo examina el fallo "Lakshmi Dhikta" de la Corte Suprema de Nepal en el cual se reconoció que el aborto es un derecho fundamental protegido por la Constitución. La autora, Melissa Upreti, explica de qué maneras el fallo refleja el modelo transformativo de la igualdad consagrado en la Convención sobre la Eliminación de Todas las Formas de Discriminación contra la Mujer.

La cuarta parte recopila los escritos que exploran el significado de las narrativas producto de las leyes, los litigios y el lenguaje sobre el aborto, así como el sentido social que estas conllevan. Lisa M. Kelly presenta una serie de casos de América Latina que se refieren a violencia sexual contra niñas y/o adolescentes; analiza las narrativas de sufrimiento inocente que fueron parte de los litigios, y evalúa los costos y beneficios de este tipo de contiendas, en particular para las jóvenes protagonistas de estos casos.

En "Narrativas sobre la personalidad jurídica prenatal en la regulación del aborto", Alejandro Madrazo expone el significado del debate jurídico en México y otros países sobre la condición de persona del feto en relación con el ejercicio de los derechos reproductivos de las mujeres.

El libro concluye con el capítulo de Rebecca Cook en el cual estudia los efectos estigmatizadores de las leyes penales sobre el aborto. Se exploran las maneras en que las justificaciones normativas de la penalización del aborto crean significados sociales sobre las mujeres y se examinan las maneras en que el derecho penal formal sobre el aborto, el derecho informal y las reglas complementarias las estigmatizan. La autora finaliza respondiendo al interrogante sobre si pueden las sociedades justificar la penalización del aborto, con sus significados estigmatizadores. 
De esta manera, la obra recorre el debate jurídico y judicial en el ámbito trasnacional expresando las estrategias de sectores sociales, religiosos y políticos con intereses contrapuestos. La defensa de los derechos sexuales y reproductivos de las mujeres requiere el análisis y la compresión de estos debates, ya sea para buscar experiencias transformadoras o para elaborar estrategias de defensa, lo cual resulta imposible sin una perspectiva que aborde cuestiones como las de este libro. 
